\title{
Direction for Basal Insulin Therapy by Once Daily Injection in the Clinical Practice
}

\author{
Hiroshi Bando ${ }^{1,2^{*}}$ \\ ${ }^{1}$ Medical Research/Tokushima University, Tokushima, Japan \\ ${ }^{2} J a p a n$ Low Carbohydrate Diet Promotion Association (JLCDPA), Kyoto, Japan
}

Corresponding Author: Hiroshi BANDO, MD, PhD, FACP ${ }^{\text {ORCID iD }}$

Address: Tokushima University /Medical Research, Nakashowa 1-61, Tokushima 770-0943, Japan.

Received date: 06 January 2021; Accepted date: 10 February 2021; Published date: 17 February 2021

Citation: Bando H. Direction for Basal Insulin Therapy by Once Daily Injection in the Clinical Practice. Diab Res Open Access. 2021 Feb 17;3(1):11-15.

Copyright (c) 2021 Bando H. This is an open-access article distributed under the Creative Commons Attribution License, which permits unrestricted use, distribution, and reproduction in any medium, provided the original work is properly cited.

\begin{abstract}
American Diabetes Association (ADA) has announced the new version of the standards of Medical Care in Diabetes-2021. The guideline of the diabetic patients with Older Adults seems to be used for a wide range of clinical practice. Among them, several impressive comments were found, where "Once-daily basal insulin injection therapy is associated with minimal side effects and maybe a reasonable option in many elder patients”. Recent topic includes Dual Action of Liraglutide and insulin degludec (DUAL) studies, and Xultophy has shown beneficial efficacy. Consequently, the trend would be developed from multiple daily injection (MDI) method to once daily injection.
\end{abstract}

\section{Keywords}

American Diabetes Association (ADA), Dual Action of Liraglutide and Insulin Degludec (DUAL) studies, Xultophy, Multiple Daily Injection (MDI), Once Daily Injection

New Year 2021 has come. On January 1, American Diabetes Association (ADA) has announced the new version of the standards of Medical Care in Diabetes2021 [1]. It has 16 chapters with 222 pages. Among them, chapter 12 was for the guideline of the diabetic patients with Older Adults. In the actual medical practice, many elderly diabetic patients have been increased and treated [2]. The usual medical management for elder diabetic patients requires an adequate assessment of medical, functional, psychological, and social aspects, which means biopsycho-social domains [3]. Then, the treatment guideline for them would be the most common problem. From the current situation, several useful and impressive information will be introduced in this article.

Firstly, Diabetes has been highly prevalent for the elderly population. In $>65$ years old, more than onequarter of adults show diabetic and one-half of them show prediabetes. Diabetic condition has a close relationship with geriatric syndromes, including cognitive impairment, depression, persistent pain, falls, urinary incontinence, and polypharmacy. These problems usually aggravate QOL and self-management (level B) [4].

Lifestyle management included the recommendation of optimal nutrition and protein intake [5], aerobic activity, weight-bearing exercise, resistance training. 
Furthermore, several intensive lifestyle interventions should be considered such as dietary changes, physical activity, and weight reduction about 5-7\%. These can be beneficial on QOL [6], physical functioning and mobility [7], and cardiometabolic risk factor control [8] (level A).

Secondly, the crucial points of pharmacological therapy recommendations include i) select oral hypoglycemic agents (OHA) with low risk of hypoglycemia, ii) avoid overtreatment common in elder diabetic adults [9], iii) make simplification of complex regimens [10], iv) consider necessary costs of care and insurance coverage for developing therapeutic plans.

For OHA, metformin is the first-line agent, which can be safely provided when $\mathrm{eGFR} \geqq 30 \mathrm{ml} / \mathrm{min} / 1.73 \mathrm{~m}^{2}$. Dipeptidyl peptidase- 4 inhibitor (DPP-4i) has a low reverse effect such as hypoglycemia but rather expensive [11]. Sodium 2 Glucose Cotransporter 2 Inhibitors (SGLT2i) are beneficial for cardiovascular disease, heart failure, and CKD progression [12]. Glucagon-like peptide 1 receptor agonists (GLP-1Ra) are beneficial for patients with established cardiovascular disease [13]. Liraglutide Effect and Action in Diabetes: Evaluation of Cardiovascular Outcome Results (LEADER) trial showed the improved outcomes when cases are $>50$ years with CVD (HR o.83) [14]. In contrast, cases $>60$ years with no CVD showed various adverse events observed, such as nausea, vomiting, and diarrhea (HR 1.20).

Thirdly, several beneficial treatment protocols concerning insulin therapy will be described [2].

1) Concerning the insulin therapy, rather a breakthrough comment was found. "Once-daily basal insulin injection therapy is associated with minimal side effects and maybe a reasonable option in many older patients“. Multiple daily injections (MDI) of insulin may be too complex for the older patient, who has already advanced complications, coexisting chronic illnesses, or impaired functional status. The insulin regimen is recommended to become more simply protocol. The Algorithm is shown for an adequate insulin regimen for older T2DM. Basal insulins include glargine U-100, U-30o, detemir, degludec and human NPH [15]. For better glucose variability, titrate dose of basal insulin on average fasting fingerstick data over a week. The goal is $90-150$ $\mathrm{mg} / \mathrm{dL}$ (5.0-8.3 mmol/L) [1].

2) An important comment is found for mealtime insulin. If mealtime insulin is $>10$ units/dose, decrease dose 50\% and add noninsulin agents. If it is $\leq 10$ units/dose, discontinue mealtime insulin and add noninsulin agents. After that, adequate management includes the evaluation of the estimated glomerular filtration rate (eGFR). When eGFR is $\geq 45 \mathrm{~mL} / \mathrm{min} / 1.73 \mathrm{~m}^{2}$, start metformin 50omg daily and increase dose every 2 weeks. When eGFR is $<45 \mathrm{~mL} / \mathrm{min} / 1.73 \mathrm{~m}^{2}$, diabetic patient has been already on metformin, or metformin is not tolerated, proceed to the second-line OHA [16].

3) Some additional tips are included. When adjusting mealtime insulin, use simplified sliding scale. If premeal glucose $>250(<350) \mathrm{mg} / \mathrm{dL}$, provide 2(4) units of short- or rapid-acting insulin. Stop sliding scale method when not needed daily [2].

Fourthly, three patterns of patient status were classified, which are i) healthy, ii) complex/intermediate and iii) very complex/poor health [17]. Treatment goals of HbA1c, fasting glucose and blood pressure are shown as follows.

1) Healthy: It shows intact cognitive and functional status with longer remaining life expectancy, where $7.0-7.5 \%$, 80-130 mg/dL, 140/90 mmHg with statin (unless contraindicated or not tolerated).

2) Complex/intermediate: It shows multiple coexisting chronic illnesses, mild-to-moderate cognitive impairment, hypoglycemia vulnerability and fall risk. The target points are 8.0\%, 90-150 $\mathrm{mg} / \mathrm{dL}, 140 / 90 \mathrm{mmHg}$ with statin (unless contraindicated or not tolerated).

3) Very complex/poor health: It shows moderate-to severe cognitive impairment [18] or ADL impairments, associated with uncertain benefit for life expectancy. Avoid reliance on HbA1c value, and diabetic management is based on avoiding hypoglycemia and symptomatic 
hyperglycemia. The target goal includes 100-180 $\mathrm{mg} / \mathrm{dL}, 150 / 90 \mathrm{mmHg}$ with the consideration of possible benefit with statin. For diabetic patients with mild cognitive impairment (MCI), the trial of intranasal insulin and metformin therapy had provided insights for future developing studies [19].

From mentioned above, recent topic includes the changes from MDI method to once daily injection as possible. The background to this would be the spread of basal insulin and the clinical application of Zultophy as a combination of insulin and GLP-1Ra. It is Insulin Degludec/Liraglutide (IDegLira, Xultophy) which is a fixed-ratio combination (FRC) for convenient and useful clinical efficacy [20]. There were a series of Dual Action of Liraglutide and insulin degludec (DUAL) studies on Xultophy. DUAL ii Japan was conducted for phase 3a randomized treat-to-target trial for half year [21]. The results revealed that the mean HbA1c/weight reduction was $1.6 \% / 1.5 \mathrm{~kg}$, respectively for 6 months. Another study for Xultophy $(n=413)$ showed that HbA1c change for 6 months was $-0.16 \%$ as basal $\mathrm{HbA1c}$ $<9 \%$, and $-1.67 \%$ as basal HbA1c $\geq 9 \%$, respectively [22]. Furthermore, BMI showed -0.46\% for those with less than 30 , and $-0.75 \%$ for those 30 or more than 30 . Authors have reported the effects of Xultophy for patients with diabetes and chronic renal failure [23,24]. The useful add-on therapy (AOT) to diabetes would be useful for future treatment for diabetes with the satisfaction of patients [25].

\section{References}

[1] Introduction: Standards of Medical Care in Diabetes-2021. Diabetes Care. 2021 Jan;44(Suppl 1):S1S2. [PMID: 33298409]

[2] American Diabetes Association. 12. Older Adults: Standards of Medical Care in Diabetes-2021. Diabetes Care. 2021 Jan;44(Suppl 1):S168-S79. [PMID: 33298423]

[3] Young-Hyman D, de Groot M, Hill-Briggs F, Gonzalez JS, Hood K, Peyrot M. Psychosocial Care for People With Diabetes: A Position Statement of the American Diabetes Association. Diabetes Care. 2016 Dec;39(12):2126-40. Erratum in: Diabetes Care. 2017 Feb;40(2):287. Erratum in: Diabetes Care. 2017 May;40(5):726. [PMID: 27879358]
[4] Laiteerapong N, Huang ES. Diabetes in older adults. Diabetes in America. 3rd ed. Bethesda, MD: National Institutes of Health. 2018:16.

[5] Villareal DT, Aguirre L, Gurney AB, Waters DL, Sinacore DR, Colombo E, Armamento-Villareal R, Qualls C. Aerobic or Resistance Exercise, or Both, in Dieting Obese Older Adults. N Engl J Med. 2017 May 18;376(20):1943-55. [PMID: 28514618]

[6] Simpson FR, Pajewski NM, Nicklas B, Kritchevsky S, Bertoni A, Ingram F, Ojeranti D, Espeland MA; Indices for Accelerated Aging in Obesity and Diabetes Ancillary Study of the Action for Health in Diabetes (Look AHEAD) Trial. Impact of Multidomain Lifestyle Intervention on Frailty Through the Lens of Deficit Accumulation in Adults with Type 2 Diabetes Mellitus. J Gerontol A Biol Sci Med Sci. 2020 Sep 25;75(10):192127. [PMID: 31559418]

[7] Espeland MA, Gaussoin SA, Bahnson J, Vaughan EM, Knowler WC, Simpson FR, Hazuda HP, Johnson KC, Munshi MN, Coday M, Pi-Sunyer X. Impact of an 8-Year Intensive Lifestyle Intervention on an Index of Multimorbidity. J Am Geriatr Soc. 2020 Oct;68(10):2249-56. [PMID: 33267558]

[8] Look AHEAD Research Group, Gregg EW, Jakicic JM, Blackburn G, Bloomquist P, Bray GA, Clark JM, Coday M, Curtis JM, Egan C, Evans M, Foreyt J, Foster G, Hazuda HP, Hill JO, Horton ES, Hubbard VS, Jeffery RW, Johnson KC, Kitabchi AE, Knowler WC, Kriska A, Lang W, Lewis CE, Montez MG, Nathan DM, Neiberg RH, Patricio J, Peters A, Pi-Sunyer X, Pownall H, Redmon B, Regensteiner J, Rejeski J, Ribisl PM, Safford M, Stewart K, Trence D, Wadden TA, Wing RR, Yanovski SZ. Association of the magnitude of weight loss and changes in physical fitness with long-term cardiovascular disease outcomes in overweight or obese people with type 2 diabetes: a post-hoc analysis of the Look AHEAD randomised clinical trial. Lancet Diabetes Endocrinol. 2016 Nov;4(11):913-21. [PMID: 27595918]

[9] McAlister FA, Youngson E, Eurich DT. Treatment Deintensification Is Uncommon in Adults With Type 2 Diabetes Mellitus: A Retrospective Cohort Study. Circ Cardiovasc Qual Outcomes. 2017 Apr;10(4):eoo3514. [PMID: 28416531]

[10] Abdelhafiz AH, Sinclair AJ. Deintensification of hypoglycaemic medications-use of a systematic review approach to highlight safety concerns in older people 
with type 2 diabetes. J Diabetes Complications. 2018 Apr;32(4):444-50. [PMID: 29274807]

[11] Davies MJ, D'Alessio DA, Fradkin J, Kernan WN, Mathieu C, Mingrone G, Rossing P, Tsapas A, Wexler DJ, Buse JB. Management of Hyperglycemia in Type 2 Diabetes, 2018. A Consensus Report by the American Diabetes Association (ADA) and the European Association for the Study of Diabetes (EASD). Diabetes Care. 2018 Dec;41(12):2669-701. [PMID: 30291106]

[12] Wiviott SD, Raz I, Bonaca MP, Mosenzon O, Kato ET, Cahn A, Silverman MG, Zelniker TA, Kuder JF, Murphy SA, Bhatt DL, Leiter LA, McGuire DK, Wilding JPH, Ruff CT, Gause-Nilsson IAM, Fredriksson M, Johansson PA, Langkilde AM, Sabatine MS; DECLARE-TIMI 58 Investigators. Dapagliflozin and Cardiovascular Outcomes in Type 2 Diabetes. $\mathrm{N}$ Engl J Med. 2019 Jan 24;380(4):347-57. [PMID: 30415602]

[13] Hernandez AF, Green JB, Janmohamed S, D'Agostino RB Sr, Granger CB, Jones NP, Leiter LA, Rosenberg AE, Sigmon KN, Somerville MC, Thorpe KM, McMurray JJV, Del Prato S; Harmony Outcomes committees and investigators. Albiglutide and cardiovascular outcomes in patients with type 2 diabetes and cardiovascular disease (Harmony Outcomes): a double-blind, randomised placebocontrolled trial. Lancet. 2018 Oct 27;392(10157):15191529. [PMID: 30291013]

[14] Gilbert MP, Bain SC, Franek E, Jodar-Gimeno E, Nauck MA, Pratley R, Réa RR, Kerr Saraiva JF, Rasmussen S, Tornøe K, von Scholten BJ, Buse JB; LEADER Publication Committee on behalf of the LEADER Trial Investigators. Effect of Liraglutide on Cardiovascular Outcomes in Elderly Patients: A Post Hoc Analysis of a Randomized Controlled Trial. Ann Intern Med. 2019 Mar 19;170(6):423-26. [PMID: 30508430]

[15] Marso SP, McGuire DK, Zinman B, Poulter NR, Emerson SS, Pieber TR, Pratley RE, Haahr PM, Lange M, Brown-Frandsen K, Moses A, Skibsted S, Kvist K, Buse JB; DEVOTE Study Group. Efficacy and Safety of Degludec versus Glargine in Type 2 Diabetes. N Engl J Med. 2017 Aug 24;377(8):723-32. [PMID: 28605603]

[16] Out M, Kooy A, Lehert P, Schalkwijk CA, Stehouwer CDA. Long-term treatment with metformin in type 2 diabetes and methylmalonic acid: Post hoc analysis of a randomized controlled 4.3year trial. J Diabetes Complications. 2018 Feb;32(2):171-78. [PMID: 29174300]

[17] Seidu S, Kunutsor SK, Topsever P, Hambling CE, Cos FX, Khunti K. Deintensification in older patients with type 2 diabetes: A systematic review of approaches, rates and outcomes. Diabetes Obes Metab. 2019 Jul;21(7):1668-79. [PMID: 30938038]

[18] Alagiakrishnan K, Sankaralingam S, Ghosh M, Mereu L, Senior P. Antidiabetic drugs and their potential role in treating mild cognitive impairment and Alzheimer's disease. Discov Med. 2013 Dec;16(90):277-86. [PMID: 24333407]

[19] Craft S, Baker LD, Montine TJ, Minoshima S, Watson GS, Claxton A, Arbuckle M, Callaghan M, Tsai E, Plymate SR, Green PS, Leverenz J, Cross D, Gerton B. Intranasal insulin therapy for Alzheimer disease and amnestic mild cognitive impairment: a pilot clinical trial. Arch Neurol. 2012 Jan;69(1):29-38. [PMID: 21911655]

[20] Heo YA. Insulin degludec/liraglutide in type 2 diabetes: a profile of its use. Drugs \& Therapy Perspectives. 2020 Jun;36(6):219-29.

[21] Watada H, Ross Agner BF, Doshi A, Bardtrum L, Ranthe MF, Billings LK. IDegLira Improves Glycemic Control in Japanese Patients with Uncontrolled Type 2 Diabetes on Premixed Insulin Therapy. Diabetes Ther. 2020 Jan;11(1):331-39. [PMID: 31760599]

[22] Melzer-Cohen C, Chodick G, Naftelberg S, Shehadeh N, Karasik A. Metabolic Control and Adherence to Therapy in Type 2 Diabetes Mellitus Patients Using IDegLira in a Real-World Setting. Diabetes Ther. 2020 Jan;11(1):185-96. [PMID: 31808132]

[23] Fujikawa T, Kato Y, Bando H, Kakutani H, Kawata T, Yamamoto M, Wada K, Ishikura K, Shirai Y, Narutaki M, Matsuzaki S, Waka S. The Administration of Xultophy for Diabetic Patients on Hemodialysis. Diab Res Open Access. 2020 Oct 20;2(3):72-78

[24] Kato Y, Bando H, Yamashita H, Yada S, Tokuhara

$\mathrm{S}$, Tokuhara H, Mutsuda T. Impressive clinical course of diabetic patient with various medical problems and remarkable improvement by insulin degludec and liraglutide (Xultophy). MOJ Clin Med Case Rep. 2020 Apr 30;10(2):48-51.

[25] Bando H. New era for useful add-on therapy 
Citation: Bando H. Direction for Basal Insulin Therapy by Once Daily Injection in the Clinical Practice. Diab Res Open Access. 2021 Feb 17;3(1):11-15.

\section{Editorial}

(AOT) to diabetes by combined agents of insulin and glucagon-like peptide-1 receptor agonist (GLP-1RA). Int Med. 2020;2(5):264-66.

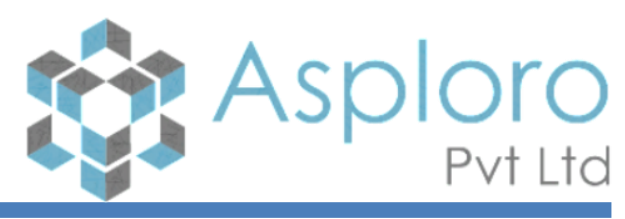

Keywords: American Diabetes Association (ADA), Dual Action of Liraglutide and Insulin Degludec (DUAL) studies, Xultophy, Multiple Daily Injection (MDI), Once Daily Injection 